Article

\title{
Smart Shipboard Power System Operation and Management
}

\author{
Fotis D. Kanellos ${ }^{1, *}$, Amjad Anvari-Moghaddam ${ }^{2}$ and Josep M. Guerrero ${ }^{2}$ \\ 1 School of Production Engineering \& Management, Technical University of Crete, Chania GR-73100, Greece \\ 2 Department of Energy Technology, Aalborg University, Aalborg 9220, Denmark; \\ aam@et.aau.dk (A.A.-M.); joz@et.aau.dk (J.M.G.) \\ * Correspondence: fkanellos@dpem.tuc.gr; Tel.: +30-2821-037-339
}

Academic Editor: Chien-Hung Liu

Received: 18 August 2016; Accepted: 24 October 2016; Published: 2 November 2016

\begin{abstract}
During recent years, optimal electrification of isolated offshore systems has become increasingly important and received extensive attention from the maritime industry. Especially with the introduction of electric propulsion, which has led to a total electrification of shipboard power systems known as all-electric ships (AESs), the need for more cost-effective and emission-aware solutions is augmented. Such onboard systems are prone to sudden load variations due to the changing weather conditions as well as mission profile, thus they require effective power management systems (PMSs) to operate optimally under different working conditions. In this paper, coordinated optimal power management at the supply/demand side of a given AES is studied with regard to different objectives and related technical/environmental constraints. The optimal power management problem is formulated as a mixed-integer nonlinear programming (MINLP) model and is solved using a metaheuristic algorithm. To show the effectiveness and applicability of the proposed PMS, several test scenarios are implemented and related simulation results are analyzed and compared to those from conventional methods.
\end{abstract}

Keywords: all-electric ship; coordinated energy management; constrained optimization; metaheuristic algorithm

\section{Introduction}

During the last couple of years, the increasing nature of energy demand in modern ships together with the growing needs for better energy conservation and environmental protection have driven the initiative to pursue all-electric ship (AES) configurations [1-5]. Within the maritime industry, AES is expected to modify the existing ways of power production, distribution and consumption for the onboard energy subsystems and to create a paradigm shift in the processes of monitoring, control and conserving energy through utilizing electrical power for propulsion and service loads [6]. Moreover, AES is envisaged to become an appealing technology with great potential for both fuel and emission reductions in comparison with conventional ship power systems [7]. In an AES, the electric motor-driven systems substitute the main diesel propulsion while the required electrical power is provided by different sources such as steam or diesel engines, gas turbines (GTs), fuel cells (FCs), energy storage systems (ESS) and possibly renewable-based prime movers such as photovoltaic systems (PVs), allowing a high efficiency throughout the whole range of operation with respect to vessel speed.

One of the main challenges with AES is to design and incorporate a power management system (PMS) for optimal scheduling of the on-board power plants and electric loads. Well-planned operation of a shipboard electrical system at the supply side (in terms of optimal engine loading), together with efficient scheduling of loads, in particular the electric propulsion demand, can affect the overall system 
efficiency and ensure economic/environmental benefits. More importantly, PMS can coordinate controllable power sources and loads in a way to meet the system's dynamic requirements for short-run intervals.

With regard to a shipboard PMS design and control, extensive research works have been initiated recently and many researchers around the world have elaborated on the issues involved [8-20]. For example, in [8] the economic operation of a vessel equipped with PVs and ESSs is studied for different power supply architectures, and analytic formulas are reported for calculating the system marginal cost, taking into account the energy and power balances for a given time period. The same optimal power generation scheduling for a shipboard power system with and without energy storage options is presented in [9] and the system behavior is investigated under each working scenario, accordingly. In $[10,11]$, a model predictive control (MPC)-based PMS for an onboard power system that includes multiple power sources and loads, such as the ship propulsion system and high power pulsed-type electrical load, is proposed and formulated as a real-time optimization problem where minimum cost of operation is considered as the objective. Similar real-time optimal dispatch of an AES enabled by integrated power systems is proposed in [11] and formulated as a simplified two-level optimization problem for improved computational efficiency. Moreover, to get better insight into the performance of the proposed approach, tradeoffs between the computational efficiency and optimization accuracy are also analyzed by the authors. Considering the same subject area, a simulation platform is developed in [12] for system-level studies of hybrid electric ships. The paper is focused on modeling and simulation of different onboard components (such as synchronous generator-rectifier system, inverter, DC/DC converters, diesel engines, propeller, and ship hydrodynamics), while optimal management and power sharing control mechanism for the whole system is described for a number of operating scenarios. An integrated security-constrained power management strategy is also presented in [13] for an AES during the normal/alert operating state. In this paper, the optimal power management problem is formulated as a multi-objective problem and is solved by using a population-based optimization algorithm during the study period. Although the proposed method could effectively operate the system close to its optimal condition, the computational efficiency of the algorithm in terms of run-time is not satisfactory. Other power management strategies for shipboard systems are also outlined in related literature using mathematical programming [14-19], agent-based approaches [20-22], and hierarchical control methodologies [23].

This paper proposes a practical framework for optimal power management in an AES with regard to different objectives and related technical/environmental constraints. The optimal management problem is formulated as a mixed-integer nonlinear programming (MINLP) model and is solved using a metaheuristic algorithm based on Particle Swarm Optimization (PSO). To show the applicability and superior performance of the proposed PMS, several test scenarios based on a RO-PAX ferry with integrated full electric propulsion and realistic constraints are presented, and related simulation results are analyzed and compared to those from conventional models.

The main contributions of this paper can be summarized as follows:

- Shipboard PMS is designed not only to ensure economic operation of the vessel under any working condition, but also to meet the pollutants emission constraints according to the available standards. It is noted that energy efficiency indices adopted by IMO do not include $\mathrm{NO}_{x}$ and $\mathrm{SO}_{x}$ and are focused on $\mathrm{CO}_{2}$ emissions.

- Power scheduling within the AES is considered simultaneously at the supply and demand sides and their system-level interaction is modeled accordingly, i.e., the propulsion load at the demand side is appropriately adjusted so that the optimal points of operation of the electric generators at the supply side are approached.

The rest of the paper is organized as follows. Section 2 describes the ship power system economic and environment-friendly operation modeling, the formulation of shipboard power management with environmental constraints and the solution of the power management problem by using PSO. 
Moreover, AES power system configuration is briefly described. In Section 3 simulation results from the proposed PMS applied to AES are presented. In Section 4 the results are discussed and final conclusions are drawn in Section 5.

\section{Materials and Methods}

\subsection{Ship Power System Economic and Environment-Friendly Operation Modeling}

A generic diagram of the fully electrified shipboard power system examined in this paper is shown in Figure 1. In this configuration the produced electric power supplies mainly the electric propulsion motors and ship service load. Ship propulsion is provided by large electric motors driven by power electronic converters that enable continuous shaft variable speed operation in a wide speed range, operational flexibility and fuel economy. Also, the need for large shafts for the coupling of propellers and prime movers and the use of mechanical gearboxes is eliminated.

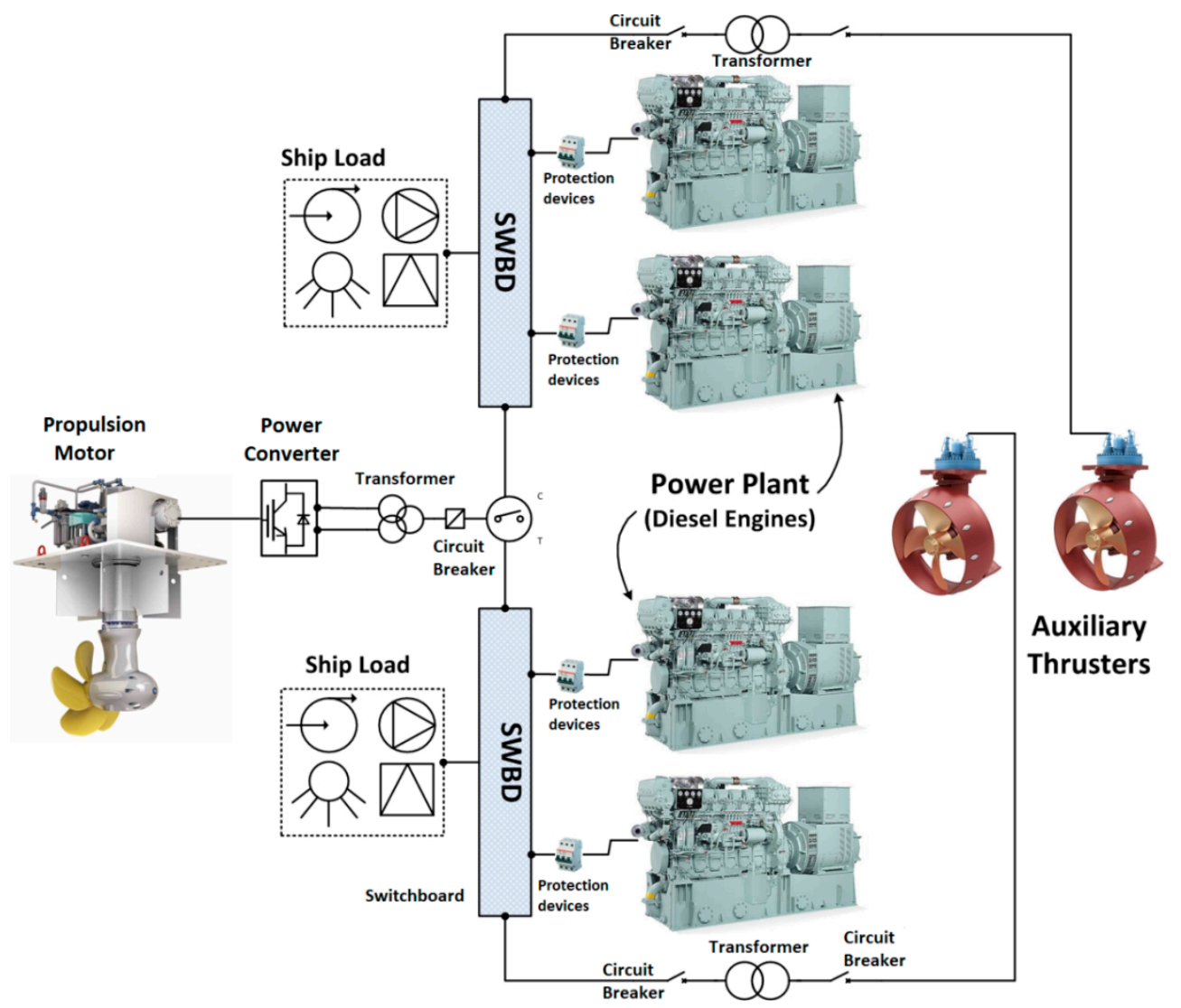

Figure 1. Generic diagram of a fully electrified shipboard power system.

Traditional ships as well as AES must employ a well-designed Ship Energy Efficiency Management Plan (SEEMP). In the near future the major targets of SEEMP will be operation cost minimization and gas emission limitation. So far SEEMPs are focused on $\mathrm{CO}_{2}$. Hence, $\mathrm{CO}_{2}$ emissions limitation is examined in this paper. However, the formulation of the problem can be easily generalized and other pollutants beyond $\mathrm{CO}_{2}$ can be included in the future.

The targets of operation cost minimization and GHG emissions limitation might conflict with each other, making the optimal power management in AES a very challenging problem. In this context, if propulsion power is appropriately adjusted in a way to meet AES operation constraints, it could greatly contribute to the improvement of ship power system efficiency. Propulsion load adjustment can also contribute to the limitation of GHG emissions in real time. In the following, 
introductory information about ship power system operation cost, propulsion power and energy efficiency estimation is provided.

The fuel consumption (FC) of any onboard thermal unit may accurately be approximated by a second-order polynomial of its produced power $P_{i}$ as following:

$$
F C_{i}\left(P_{i}\right)=a_{0 i}+a_{1 i} \cdot P_{i}+a_{2 i} \cdot P_{i}^{2}
$$

The total variable cost of the power plant $\left(T o C_{e}\right)$ is calculated by taking into account the fuel $\operatorname{cost}\left(F C_{i}\right)$, the maintenance cost per power unit $\left(M C_{i}\right)$ and the start-up/shut-down cost $\left(S C_{i j}\right)$ of the $i$-th generator, producing active power $P_{i j}$ during a time interval $\Delta T_{j}$, with the assumption that the generator is running:

$$
T o C_{e}=\sum_{j=1}^{T} \sum_{i=1}^{N_{E}}\left(S t_{i j} \cdot\left(F c_{i} \cdot S F C_{i}\left(P_{i j}\right)+M C_{i}\right) \cdot P_{i j} \cdot \Delta T_{j}+S C_{i j}\left|S t_{i j}-S t_{i, j-1}\right|\right)
$$

where $T$ is the total time period under study, $S F C_{i}\left(P_{i}\right)=F C_{i}\left(P_{i}\right) / P_{i}$ is specific fuel consumption, $S t_{i j}$ is equal to 1 if unit $i$ is operating, otherwise 0 and $N_{E}$ is the total number of electric generators.

Ship load consists of propulsion and service load. For the purposes of this work, ship load can be approximated by using the ship speed-propulsion power curve. This curve depends on hull resistance at specific conditions and it can be satisfactorily approximated by the following equation $[24,25]$ :

$$
P_{\text {Prop }}=c_{P 1} \cdot V^{c_{P 2}}
$$

where $V$ is ship velocity, $P_{\text {Prop }}$ is the required propulsion power to develop velocity $V$, coefficient $c_{P 1}$ is used for propulsion power and ship velocity matching, and $c_{P 2}$ is a constant depending on hull form.

Any deviation of the optimal ship speed from its optimal value during time interval $\Delta T_{j}$ from the scheduled one will result in a respective deviation of the optimal propulsion power $\Delta P_{\text {Prop }, j}$ from its scheduled value.

Hence, the respective deviation from the initially scheduled travelled distance at the end of the time interval $\Delta T_{j}$ is given by:

$$
\Delta S_{j}=\sum_{t=1}^{j}\left(V_{t, o p t}-V_{t}\right) \cdot \Delta T_{t}
$$

The optimal adjustment of the propulsion power should be performed jointly with the optimization of the electric power generation. This problem comprises the sub-problems of unit commitment and optimal power dispatch. Well-known methods, like Lagrange method, can be used to solve the optimal power dispatch problem; that is, to define the optimum amounts, $P_{i}$, of the electric power generated by the ship electric generators in order to minimize the operation cost in a time interval $\Delta T$. Unit commitment process defines which generators will be in operation and when during the examined time period, while the share of load that each generator serves is calculated by optimal power dispatch.

The method promoted by the International Maritime Organization (IMO) in order to assess ship operation efficiency is based on the calculation of the Energy Efficiency Operation Indicator (EEOI) $[26,27]$. EEOI is defined as:

$$
\mathrm{EEOI}=\frac{m \mathrm{CO}_{2}}{\text { transport work }}
$$

where $m \mathrm{CO}_{2}$ is the $\mathrm{CO}_{2}$ mass produced during ship power system operation.

As can be seen in Equation (5), EEOI is the ratio of $\mathrm{CO}_{2}$ mass emitted and the transport work. It indirectly represents ship operational efficiency, as according to the efficiency definition the required consumed energy to produce the relative transport work should be used. However, $\mathrm{CO}_{2}$ mass is at 
an extent proportional to the consumed fuel (energy). Hence, ship operational efficiency and $\mathrm{CO}_{2}$ emissions are both represented in EEOI in a balanced way.

In this paper, ship energy efficiency operation indicators EEOI ${ }_{s}$ and $\mathrm{EEOI}_{\mathrm{p}}$ when ship is in the open sea or in port, respectively, are defined as follows:

$$
\begin{gathered}
\operatorname{EEOI}_{s, j}=\frac{m C O_{2}}{L F \cdot V_{j} \cdot \Delta T_{j}}=\frac{\sum_{i} c_{i} \cdot P_{i j} \cdot S F C_{i}\left(P_{i j}\right)}{L F \cdot V_{j}} \\
\operatorname{EEOI}_{p, j}=\frac{m C O_{2}}{L F \cdot \Delta T_{j}}=\frac{\sum_{i} c_{i} \cdot P_{i j} \cdot S F C_{i}\left(P_{i j}\right)}{L F}
\end{gathered}
$$

where $L F$ is ship loading factor (tns), $V_{\mathrm{j}}$ is ship speed $(\mathrm{kn})$ in the $j$-th time interval, $S F C_{i}$ is the specific fuel consumption (gFuel $/ \mathrm{kWh}$ ) of the $i$-th generator, $P_{\mathrm{ij}}$ is the power produced by $i$-th thermal unit in the $j$-th time interval $\Delta T j$ and $c_{i}$ is the conversion factor for gas emissions estimation for the $i$-th generator $\left(\mathrm{gCO}_{2} / \mathrm{gFuel}\right)$.

Ship loading factor $L F$ depends on the type of the examined ship, e.g., passenger ship, RO-PAX ferry, etc. In this study, LF is applied to a RO-PAX ferry and it is calculated as [28]:

$$
L F=\frac{n_{P}^{\prime} \cdot 0.1+n_{V}^{\prime}}{n_{P} \cdot 0.1+n_{V}} F L D
$$

where $n_{P}^{\prime}$ is the number of passengers, $n_{P}$ is the maximum number of passengers, $n_{V}^{\prime}$ is the number of carried vehicles, $n_{V}$ is the maximum number of the carried vehicles and FLD is ship full load displacement (tns).

\subsection{Formulation of Shipboard Power Management with Environmental Constraints}

Heuristic optimization methods have been proven very efficient in providing solutions to the unit commitment problem. In this paper, PSO is used to solve the optimal power generation scheduling problem. The formulation of the complex problem of the optimal power generation scheduling and demand side management is provided next.

The objective function of the examined problem is to minimize the total operation cost of AES as defined in Equation (2). This cost minimization should be done subject to several constraints. In the following the technical constraints of the examined problem are formulated. Subscripts $i, j$ denote $i$-th generator and $j$-th time interval, respectively.

- Power balance constraint,

$$
\sum_{i=1}^{N_{g}} S t_{i j} \cdot P_{i j}=\bar{L}_{j}+\Delta P_{\text {Prop }, j}, \quad \forall j
$$

where $\bar{L}_{j}$ is the average ship electric load in time interval $\Delta T_{j}$,

- Minimum and maximum generator loading constraints,

$$
P_{i, \min }<P_{i j}<P_{i, \max } \quad \forall i, j
$$

- Generator ramp rate constraint,

$$
\frac{\left|P_{i j}-P_{i, j-1}\right|}{\Delta T_{j}} \leq R c_{i, \max } \quad \forall i, j
$$

where $R c_{i, \max }$ is the maximum rate of change of the power produced by the $i$-th generator.

- Minimum operation time of a generator (minimum up-time),

$$
t_{\rightarrow \mathrm{OFF}, \mathrm{i}}-t_{\rightarrow \mathrm{ON}, \mathrm{i}} \geq \mathrm{T}_{\mathrm{ON} \_ \text {min,i, }} \quad \forall i
$$


- Minimum out of operation time of a generator,

$$
t_{\rightarrow \mathrm{ON}, \mathrm{i}}-t_{\rightarrow \mathrm{OFF}, \mathrm{i}} \geq \mathrm{T}_{\mathrm{OFF} \_ \text {min, } \mathrm{i},} \quad \forall i
$$

where $t_{\rightarrow \mathrm{OFF}, \mathrm{i}}, t_{\rightarrow \mathrm{ON}, \mathrm{i}}$ are the time points that $i$-th generator stops or starts operating, respectively. $\mathrm{T}_{\mathrm{ON} \_m i n, i}, \mathrm{~T}_{\mathrm{OFF} \_ \text {min,i }}$ are the minimum allowable operation or non-operation times of the $i$-th generator, respectively.

- Blackout prevention constraint,

$$
\sum_{i} S t_{i j} \cdot P_{i, \max }-\bar{L}_{j}-\Delta P_{\operatorname{Pro} p j} \geq \max \left\{P_{i, \max }\right\}, \quad \forall j
$$

- GHG emissions constraint,

$$
\begin{aligned}
& \frac{\sum_{i=1}^{N_{g}} c_{i} \cdot S t_{i j} \cdot P_{i j} \cdot S F C_{i}\left(P_{i j}\right)}{L F \cdot V_{j}} \leq \text { EEOI }_{\text {max }, \text { sea }}, \quad \forall j \notin \Im \\
& \frac{\sum_{i=1}^{N_{g}} c_{i} \cdot S t_{i j} \cdot P_{i j} \cdot S F C_{i}\left(P_{i j}\right)}{L F} \leq \text { EEOI }_{\text {max }, \text { port }}, \quad \forall j \in \Im
\end{aligned}
$$

where $\mathrm{EEOI}_{\max , \text { sea }}$ is the upper limit of EEOI while ship is traveling, EEOI $\mathrm{max}_{\text {,port }}$ is the upper limit of EEOI during ship port calls and $\Im$ is the set containing time intervals corresponding to ship calls at intermediate ports and the final one.

- Minimum-maximum ship speed constraint,

$$
V_{\min }<V_{j}<V_{\max }, \quad \forall j
$$

- Initial and final condition for the deviation of the actual travel distance from the scheduled one,

$$
\Delta S_{0}=0, \Delta S_{T}=0
$$

- Deviation of the actual traveled distance from the scheduled one at the intermediate ports,

$$
\Delta S_{j}=0 \quad \forall j \in \Im, \Im-1
$$

In accordance to the definition of $\Im, \Im-1$ is the set containing time intervals just before ship calls at intermediate ports and the final one.

- Minimum and maximum deviation of the actual traveled distance from the scheduled,

$$
\Delta S_{\min , j} \leq \Delta S_{j} \leq \Delta S_{\max , j}, \quad \forall j
$$

\subsection{Solution with Particle Swarm Optimization}

PSO is a stochastic optimization technique in which the trajectories of points ("particles") moving in the multidimensional space of the problem are properly adjusted. PSO has demonstrated excellent efficiency for a wide range of problems. The positions of the particles are updated over the successive executions (epochs) of the algorithm as following [29]:

$$
\begin{gathered}
v_{l}^{(k+1)}=w \cdot v_{l}^{(k)}+\alpha_{1} \cdot R N D_{1} \cdot\left(\Delta X_{l}^{\text {Pbest }}-\Delta X_{l}^{(k)}\right)+\alpha_{2} \cdot R N D_{2} \cdot\left(\Delta X^{G b e s t}-\Delta X_{l}^{(k)}\right) \\
\Delta X_{l}^{(k+1)}=\Delta X_{l}^{(k)}+v_{i}^{(k)}
\end{gathered}
$$

where $v_{l}^{(k)}$ is velocity vector of $l$-th particle at $k$-th iteration, $w$ is inertia weight factor, $\alpha_{1}$ and $\alpha_{2}$ are acceleration constants, $R N D_{1,2}$ are random numbers between 0 and $1, \Delta_{l}^{\text {Pbest }}$ is the best previous 
propulsion power deviation vector corresponding to $l$-th particle and $\Delta^{\text {Gbest }}$ is the best previous propulsion power deviation vector among all the particles. An evaluation function is used to quantify the "suitability" of particle position vector [30].

In the examined problem, each particle contains information about the operation state of ship electric generators and the deviation of the traveled distance from the non-optimized traveled distance as shown in Figure 2.

\begin{tabular}{|l|l|l|l|l|l|l|l|l|l|l|l|}
\hline $\boldsymbol{t}_{1}$ & $\Delta O S_{1}$ & $\boldsymbol{t}_{2}$ & $\Delta O S_{2}$ & $\ldots$ & $\boldsymbol{t}_{n}$ & $\Delta O S_{n}$ & $\Delta S_{1}$ & $\Delta S_{2}$ & $\Delta S_{3}$ & $\ldots$ & $\Delta S_{T}$ \\
\hline
\end{tabular}

Figure 2. Particle structure.

Where $\Delta O S_{i}$ and $\Delta S_{i}$ are numbers representing the change of the operation state of ship electric generators and the deviation of the traveled distance from the non-optimized traveled distance at the $i$-th time interval, respectively. $t_{i}$ represents the time that a change occurs in the operation state of the generators. As an illustration, let us consider that the initial operation state of the generators is represented by the number 5 , which corresponds to the binary number 101 . That means that generators 1 and 3 should be operated. Let us also consider that at time $t_{1}$ a change $\Delta S O_{1}=-2$ occurs. The new operation state is now 3 , which corresponds to the binary number 011 . This means that at the new state generator 3 should be shut down (OFF) while the rest are ON. In this way, any operation state can be represented in a very efficient way by using a relatively small particle not depending on the size of the examined system.

$\Delta S_{\mathrm{i}}$ is defined as follows,

$$
\Delta S_{i}=S_{i, o p t}-S_{i}
$$

where $S_{i, o p t}$ and $S_{i}$ are defined in (24).

$$
S_{i, o p t}=\sum_{t=1}^{i} V_{t, o p t}, \quad S_{i}=\sum_{t=1}^{i} V_{t}
$$

$V_{i}$ and $V_{i, o p t}$ are an initially planned non-optimized ship speed and the optimized ship speed at the $t$-th time interval, respectively.

The simplified solution process of the examined problem with the PSO method is given in the following pseudocode.

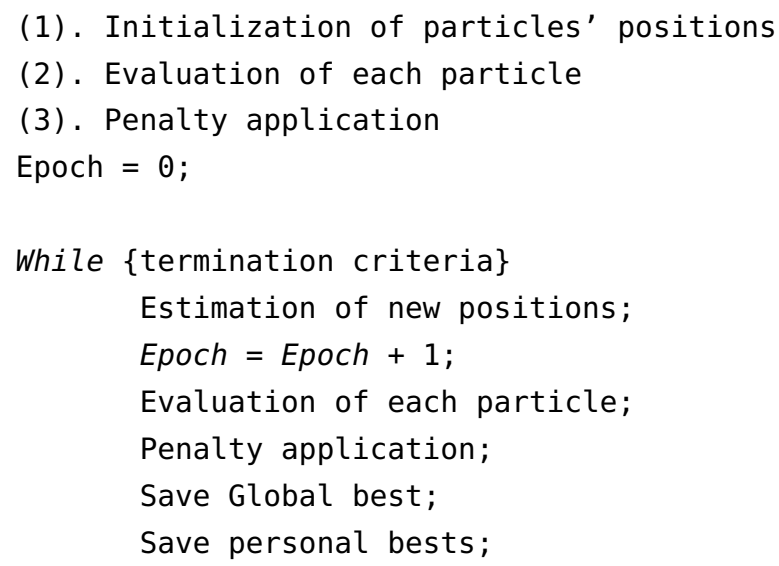

Evaluation of the best particle 


\section{Results}

\section{Case Study}

The developed optimization method is applied to a RO-PAX ferry comprising two large electric propulsion motors supplied by a set of five electrical generators. The single-line diagram of the integrated full electric propulsion system is shown in Figure 1. The technical parameters of the ship and the onboard power system are presented in Table 1.

Table 1. Ship power system data and ship parameters.

\begin{tabular}{|c|c|c|c|c|c|}
\hline \multicolumn{6}{|c|}{ Ship Electric System Parameters } \\
\hline Parameters & GEN 1 & GEN 2 & GEN 3 & GEN 4 & GEN 5 \\
\hline Nominal power $(\mathrm{MW})$ & 15 & 15 & 15 & 9 & 9 \\
\hline Generator startup/shut-down cost * (m.u. **) & $0 / 0$ & $0 / 0$ & $0 / 0$ & $0 / 0$ & $0 / 0$ \\
\hline $\begin{array}{l}\text { Generator operation cost as function of the } \\
\text { produced power }(\mathrm{m} . \mathrm{u} . / \mathrm{h})\end{array}$ & $\begin{array}{l}390+61.5 \cdot P+ \\
5.4 \cdot P^{2}\end{array}$ & $\begin{array}{c}400+63 \cdot P+ \\
5.4 \cdot P^{2}\end{array}$ & $\begin{array}{l}420+65 \cdot P+ \\
5.6 \cdot P^{2}\end{array}$ & $\begin{array}{c}430+12 \cdot P+ \\
13.1 \cdot P^{2}\end{array}$ & $\begin{array}{l}450+10 \cdot P+ \\
13.5 \cdot P^{2}\end{array}$ \\
\hline $\mathrm{CO}_{2}$ emissions $\left(\mathrm{gCO}_{2} / \mathrm{g}\right.$ fuel $)$ & 3.20 & 3.20 & 3.20 & 2.50 & 2.50 \\
\hline Technical maximum (MW) & 15 & 15 & 15 & 9 & 9 \\
\hline \multicolumn{6}{|c|}{ Ship Parameters } \\
\hline RO-PAX Ferry & No. of Vehicles $\left(n_{v}\right)$ & 700 & \multirow{3}{*}{\multicolumn{2}{|c|}{ Full Load Displacement (tns) }} & 70,000 \\
\hline Nominal speed (kn) & EEOI $_{\max 1}\left(\mathrm{gCO}_{2} / \mathrm{tn} \cdot \mathrm{kn}\right)$ & 27.5 & & & \\
\hline $\begin{array}{l}\text { Maximum number } \\
\text { of passengers }\end{array}$ & EEOI $_{\max 2}\left(\mathrm{gCO}_{2} /\right.$ tn.h $)$ & 165 & & & \\
\hline
\end{tabular}

* Diesel electric generators with negligible start-up/shut-down cost are used. ${ }^{* *}$ m.u.: monetary unit.

In this study, a $172.75 \mathrm{~nm}$ total-length route is examined with the ship stopping at one intermediate port. The number of passengers, vehicles and the corresponding ship loading factors (LF) for the two parts of the examined route are as shown in Table 2.

Table 2. Data for Ship Pay-Load.

\begin{tabular}{cccc}
\hline Part of Examined Route & Number of Passengers, $\boldsymbol{n}_{\boldsymbol{P 1}}^{\prime}$ & Number of Vehicles, $\boldsymbol{n}_{\boldsymbol{V} \mathbf{1}}^{\prime}$ & Ship Loading Factor, $\boldsymbol{L} \boldsymbol{F}$ (tns) \\
\hline Departure-Intermediate port & 1955 & 600 & 58,616 \\
Intermediate port-Final Destination & 1720 & 500 & 49,515 \\
\hline
\end{tabular}

The problem of the optimal ship power generation scheduling and load demand management is solved in two ways: by using the PSO method and dynamic programming (DP) [19,31]. In both cases the same objective and constraints, as described earlier, are taken into account. Moreover, operation scenarios with and without EEOI limitation are also examined for both optimization methods. For the PSO method the maximum number of epochs was considered to be 45 , the population of the swarm is 400 particles while the initial positions of the particles are random. From a series of simulations it was observed that after about 30 epochs of training the performance of the algorithm does not present significant change. A typical training curve is shown in Figure 3.

The initial non-optimized ship electric load for this trip can be seen in Figures 4-7, where it is compared with the results of the optimization. The power generated by each electric generator in the case of non-optimized operation is shown in Figure 4. The powers produced by the electric generators for the two examined optimization methods and operation scenarios are shown in stack form in Figures 5-8. Load sharing is obtained in all scenarios by applying the well-known Lagrange method, aiming to minimize the operation cost while satisfying at the same time technical constraints. The sum of the powers produced by generators is also compared with the non-optimized total demand in electric power in the same figures. Moreover, the evolution of ship speed, EEOI and operation cost are shown for all examined cases in Figures 9-14. In Figures 11 and 12, EEOI value when ship is at berth is divided by 10 in order to be comparable with EEOI values in the open sea. 


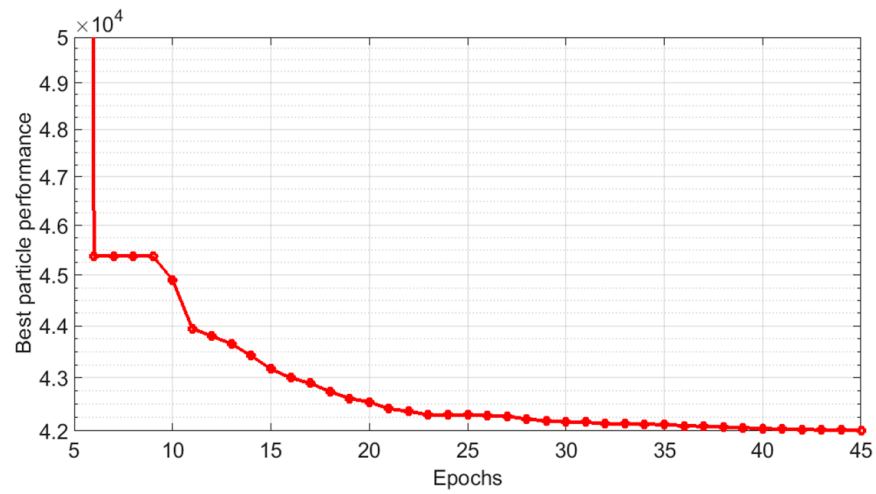

Figure 3. Performance of the best particle vs. Particle Swarm Optimization (PSO) epochs.

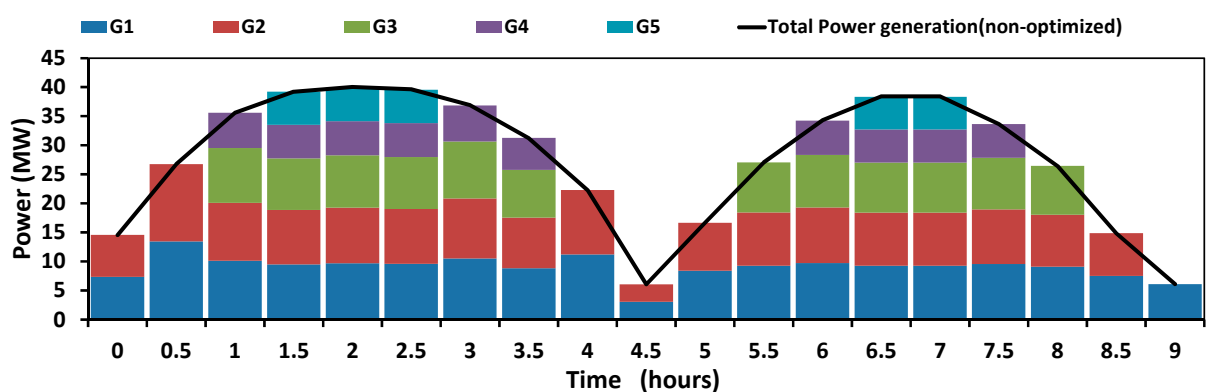

Figure 4. Optimal generator set power production (non-optimized ship power system operation).

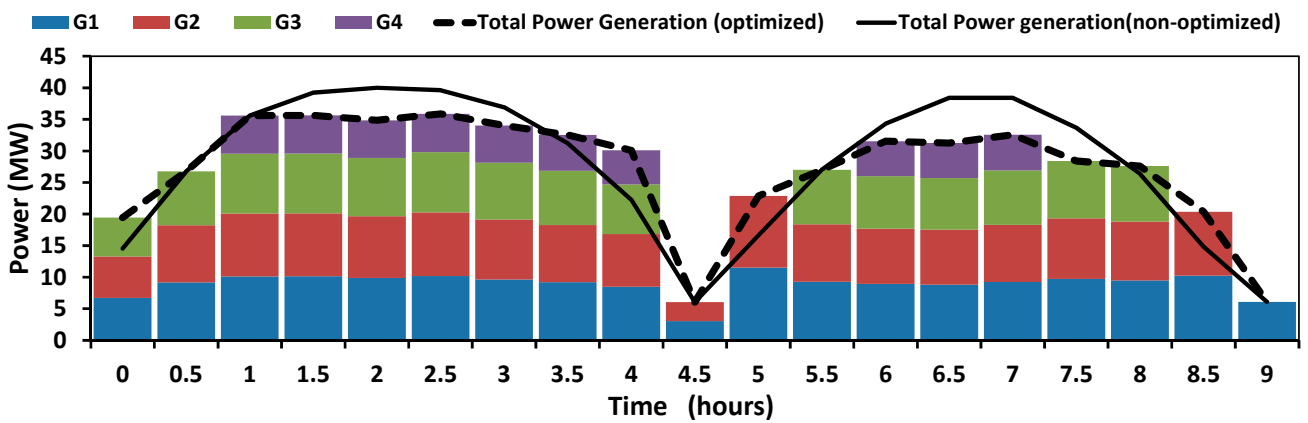

Figure 5. Optimal generator set power production, non-optimized ship electric load (dynamic programming-Energy Efficiency Operation Indicator (DP-EEOI) unlimited).

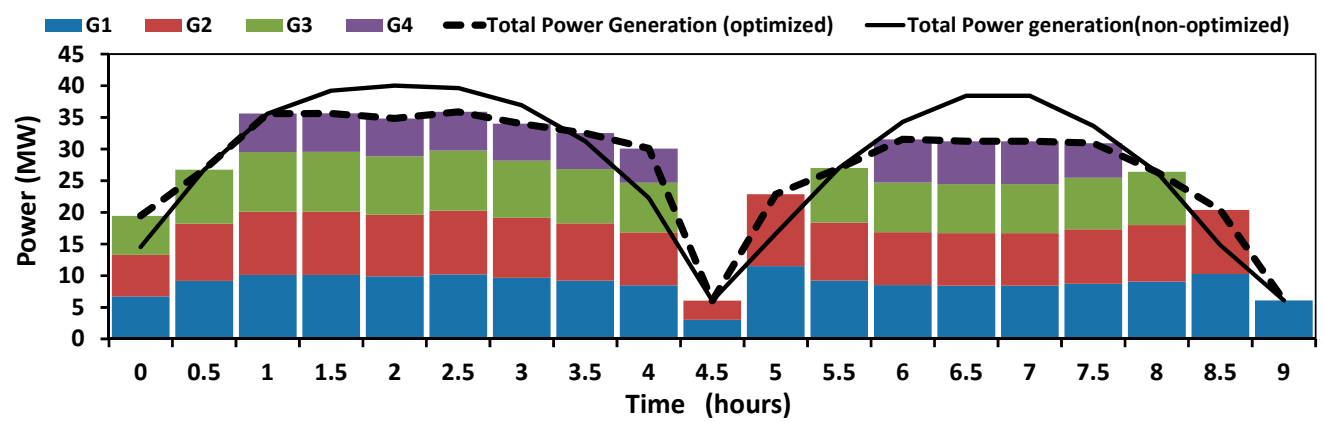

Figure 6. Optimal generator set power production, non-optimized ship electric load (DP-EEOI limited). 


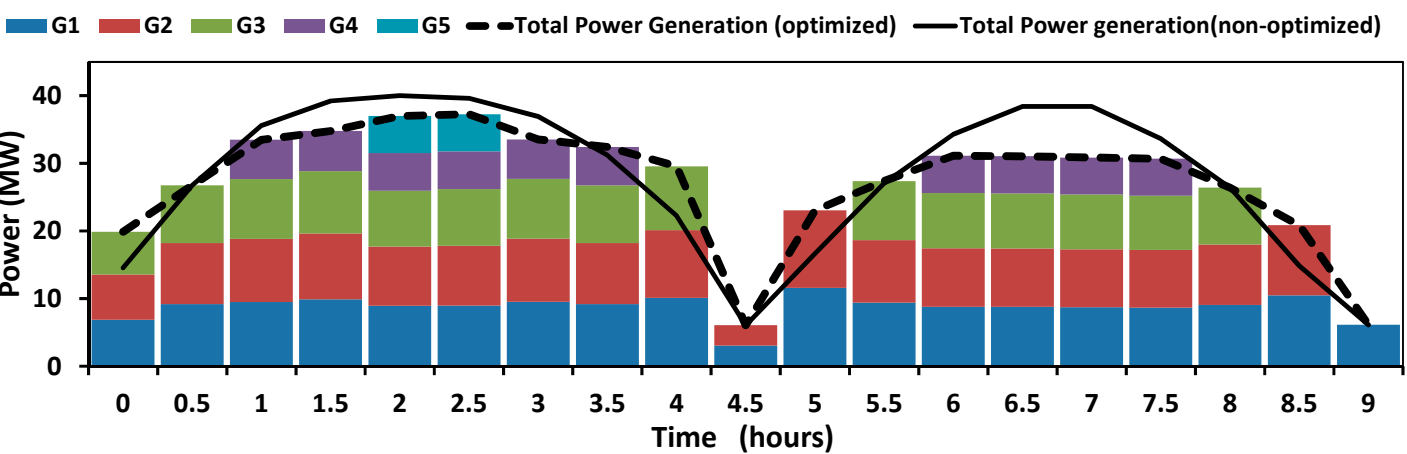

Figure 7. Optimal generator set power production, non-optimized ship electric load (PSO-EEOI unlimited).

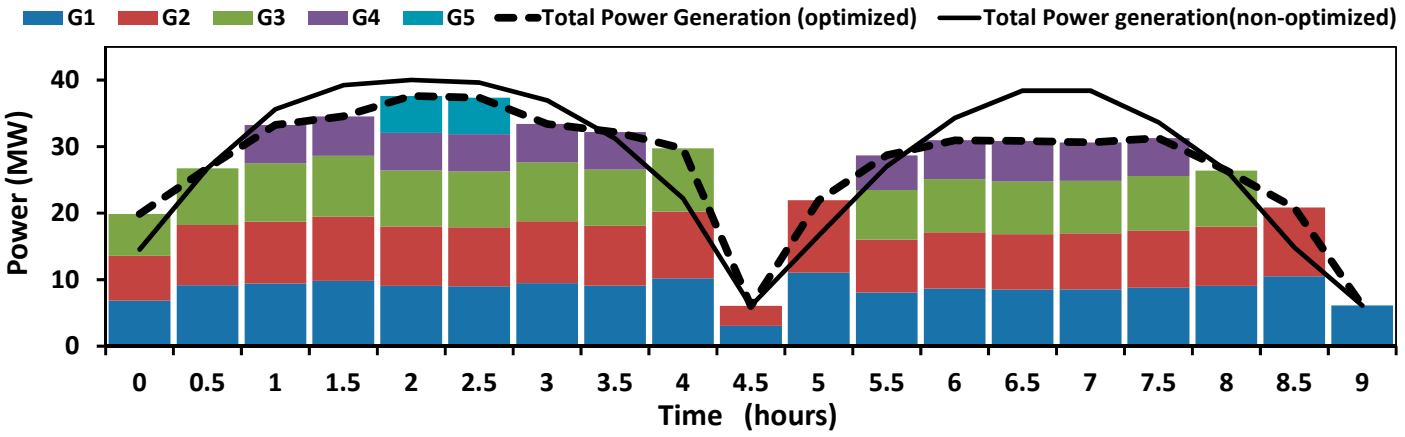

Figure 8. Optimal generator set power production, non-optimized ship electric load (PSO-EEOI limited).

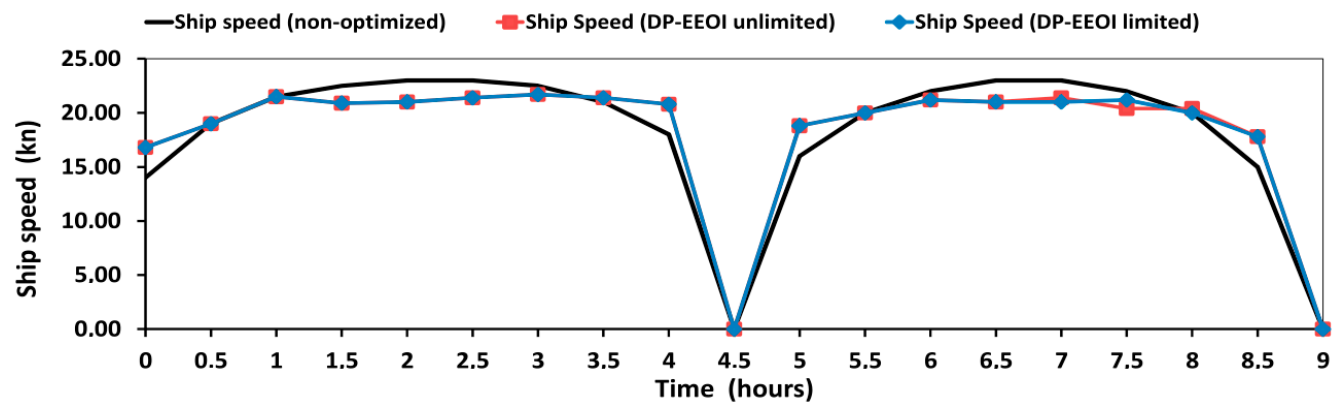

Figure 9. Ship speed (kn): DP with/without EEOI limitation.

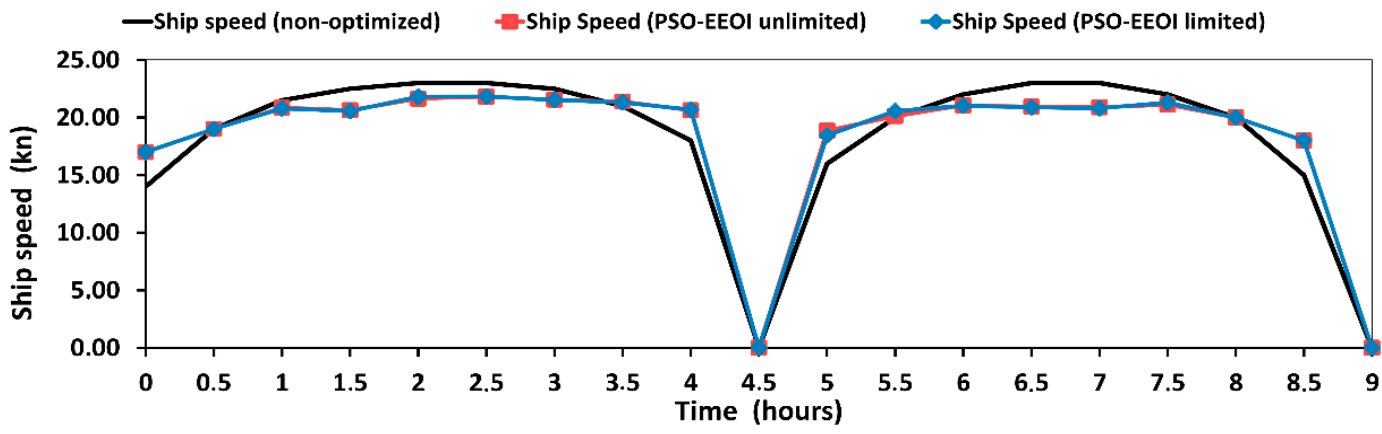

Figure 10. Ship speed (kn): PSO with/without EEOI limitation. 


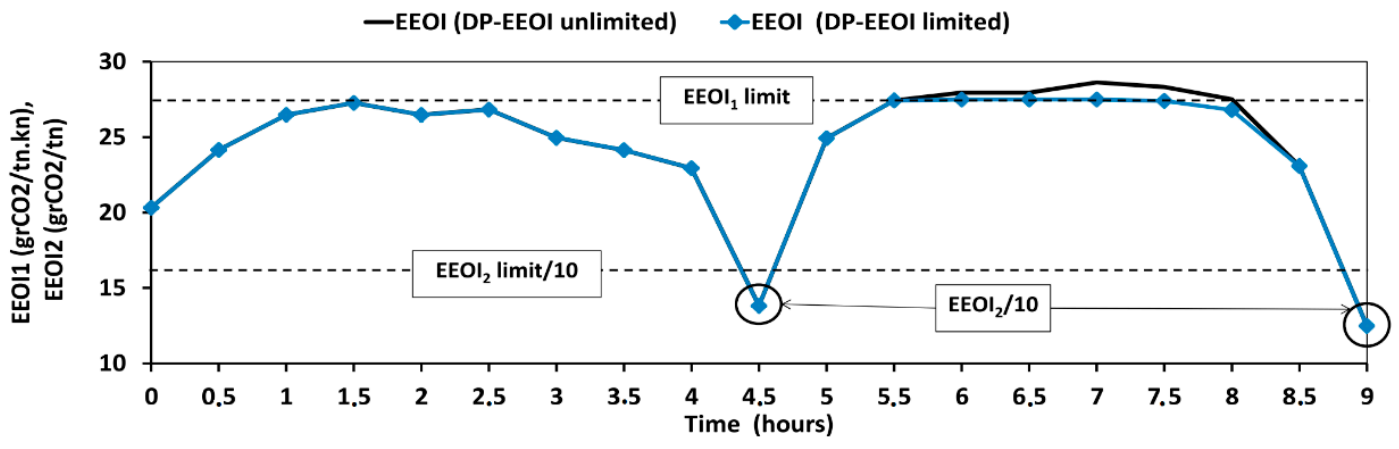

Figure 11. Ship energy efficiency operation index: DP with/without limitation.

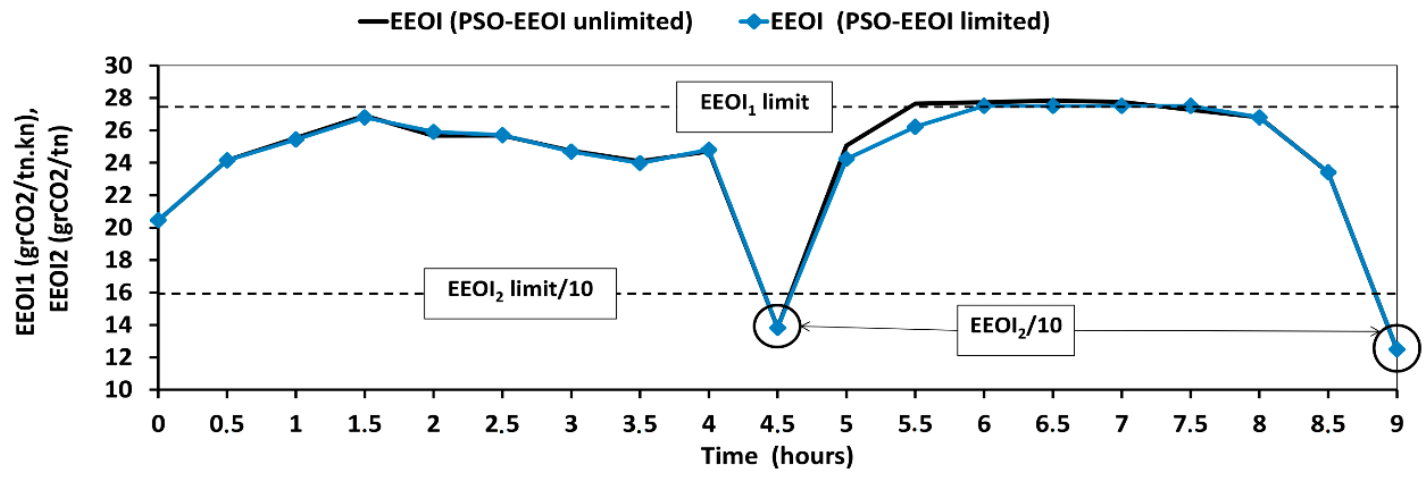

Figure 12. Ship energy efficiency operation index: PSO with/without limitation.

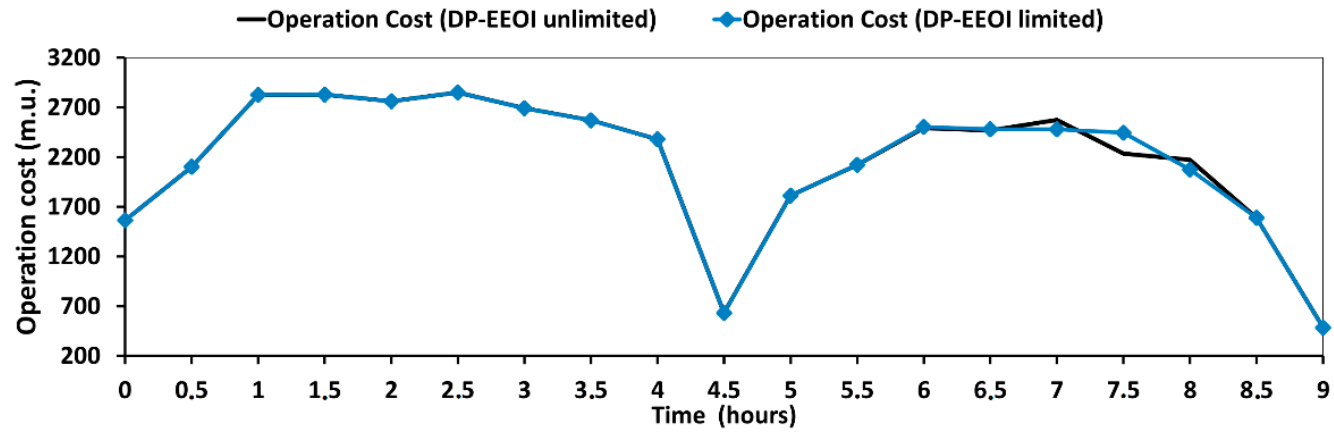

Figure 13. Ship power system operation cost (m.u.): DP with/without EEOI limitation.

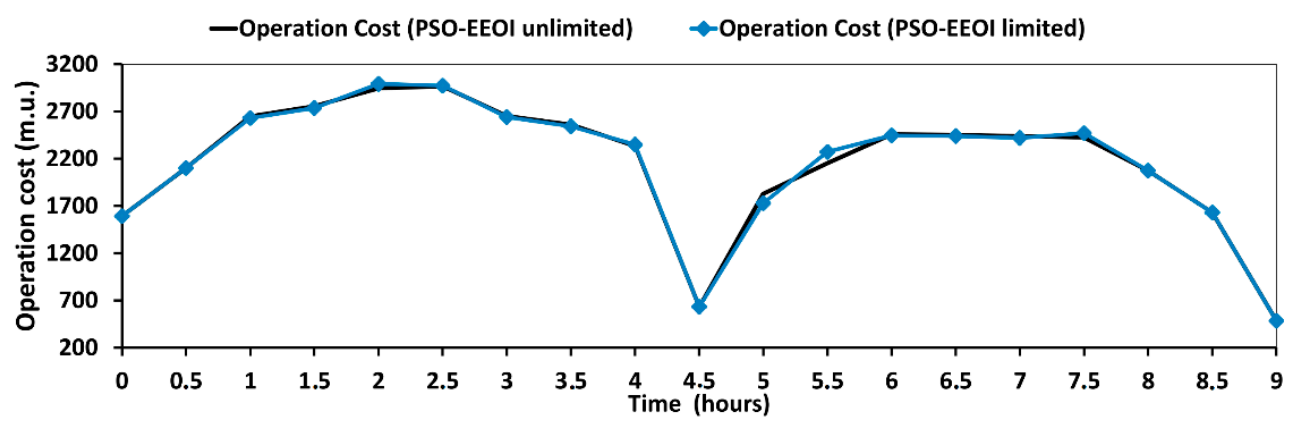

Figure 14. Ship power system operation cost (m.u.): PSO with/without EEOI limitation. 


\section{Discussion}

From the results shown in Figures $5-8$ it is concluded that both algorithms adjust properly propulsion power, and smaller deviations of total electric load occur. Generators 1 and 2 are operated continuously, while generators 3 and 4 are operated during high load periods. In time intervals with very high load, PSO puts generator 5 also into operation. This is expected to happen as generators 1 and 2 have lower operation costs than generators 3 and 4 and generator 5 is the most expensive one. However, generator 5 is useful when EEOI approximates its upper limit as generator 5 has low GHG emissions. Also, it is apparent that by using the optimization techniques less energy is required to run the system compared to a case where no optimization is applied. In other words, optimal management of generation units as well as controllable loads could save energy and decrease the operating cost of the shipboard system.

In both optimization methods, ship speed is decreased when ship is in open sea, while it is significantly increased when ship is approaching or leaving from a port in order to satisfy travelled distance constraints and to allow generators to operate more efficiently. In this way, ship speed profile becomes more flat; the same case applies also to the total electric load profile. It should be also mentioned that the ship speed deviations from the initially scheduled values are within the allowed range and the upper speed limit is not violated along the mission profile. The conditions of the traveled distance at the intermediate ports and the destination are also well satisfied.

From the obtained results it is also observed that EEOI is satisfactorily limited below its upper limit during all travel in both optimization methods, i.e., less than $27.5 \mathrm{gCO}_{2} / \mathrm{kn}$.tn for traveling in the open sea and $160 \mathrm{gCO}_{2}$ /tn.h at berth.

In the case of non-optimized operation, the total running cost of the ship power system is 42,507 m.u., while this is decreased to 41,123 m.u. in the case of using PSO without EEOI limits, and 41,150 m.u. if EEOI is limited. Respectively, the operation cost is 41,142 m.u. if dynamic programming is used and EEOI is unlimited and it slightly increases to 41,182 m.u. if EEOI is limited. Hence, it is concluded that a $3.26 \%$ reduction in operation cost is achieved with respect to non-optimized operation if PSO is applied; while in all cases PSO outperforms dynamic programming in terms of operation cost reduction. As it was expected operation cost slightly increases if EEOI is limited. It should be noted that the better performance of PSO is a result of the fact that $\Delta S$ is a discrete quantity in a dynamic programming method, thus limiting its ability to locate the global minimum with zero error.

Computation time required by PSO was almost $2200 \mathrm{~s}$ by using a computer with a CPU at $2.5 \mathrm{GHz}$, 4GB RAM and it was almost $15 \%$ longer than that of the dynamic programming method. However, it is easily concluded that if less epochs were used this would be much less without significantly affecting the operation cost. Moreover, the computation time can be significantly decreased if more powerful computational facilities are used.

\section{Conclusions}

In this paper, coordinated optimal power management at the supply/demand side of a given AES is studied with regard to different objectives and related technical/environmental constraints. The optimal power management problem is formulated as mixed-integer nonlinear programming (MINLP) model and is solved by using PSO method. The major advantage of the proposed optimization algorithm is that the size (number of dimensions) of the used particles does not depend on the size and the complexity of the examined ship power system.

To show the effectiveness and applicability of the proposed PMS, several test scenarios are implemented and related simulation results are analyzed and compared to those from conventional methods like dynamic programming. In all examined cases the operation cost obtained by using the proposed method was smaller than the one of dynamic programming.

Computation time required by PSO was almost 15\% longer than that of the dynamic programming method. However, it is easily concluded that if less epochs were used this would be much less without 
significantly affecting the operation cost. The computation time is not a substantial problem for real applications as it can be significantly decreased if more powerful computational facilities are used.

Author Contributions: Fotios D. Kanellos conceived, designed, performed the simulations and wrote part of the paper; Amjad Anvari-Moghaddam and Josep M. Guerrero analyzed the data and wrote part of the paper.

Conflicts of Interest: The authors declare no conflict of interest.

\section{References}

1. Seenumani, G.; Sun, J.; Peng, H. Real-time power management of integrated power systems in all electric ships leveraging multi time scale property. IEEE Trans. Control Syst. Technol. 2012, 20, 232-240. [CrossRef]

2. Sudhoff, S.D. Currents of change. IEEE Power Energy Mag. 2011, 1, 30-37. [CrossRef]

3. Gertsos, S.A.; Prousalidis, J.M.; Frangopoulos, C.A. Electric propulsion: From infancy to adolescence. In Proceedings of the 8th International Marine Design Conference (IMDC), Athens, Greece, 5-8 May 2003.

4. McCoy, T.J.; Amy, J.V. The state-of-the-art of integrated electric power and propulsion systems and technologies on ships. In Proceedings of the IEEE Electric Ship Technologies Symposium (ESTS), Baltimore, MD, USA, 20-22 April 2009.

5. McCoy, T.J. Trends in ship electric propulsion. In Proceedings of the IEEE Power Engineering Society Meeting, Chicago, IL, USA, 21-25 July 2002; pp. 343-346.

6. Faruque, M.O.; Dinavahi, V.; Sioderbeck, M.; Steurer, M. Geographically distributed thermo-electric co-simulation of all-electric ship. In Proceedings of the IEEE Electric Ship Technologies Symposium (ESTS), Baltimore, MD, USA, 20-22 April 2009; pp. 36-43.

7. Prousalidis, J.M.; Tsekouras, G.J.; Kanellos, F. New challenges emerged from the development of more efficient electric energy generation units. In Proceedings of the IEEE Electric Ship Technologies Symposium (ESTS), Alexandria, VA, USA, 10-13 April 2011; pp. 374-381.

8. Tsekouras, G.J.; Kanellos, F.D. Optimal operation of ship electrical power system with energy storage system and photovoltaics: Analysis and application. WSEAS Trans. Power Syst. 2013, 8, 145-155.

9. Wu, W.; Wang, D.; Arapostathis, A.; Davey, K. Optimal Power Generation Scheduling of a Shipboard Power System. In Proceedings of the IEEE Electric Ship Technologies Symposium (ESTS), Arlington, VA, USA, 21-23 May 2007; pp. 519-522.

10. Park, H.; Sun, J.; Pekarek, S.; Stone, P.; Opila, D.; Meyer, R.; Kolmanovsky, I.; DeCarlo, R. Real-time model predictive control for shipboard power management using the IPA-SQP approach. IEEE Trans. Control Syst. Technol. 2015, 23, 2129-2143. [CrossRef]

11. Banaei, M.R.; Alizadeh, R. Simulation-based modeling and power management of all-electric ships based on renewable energy generation using model predictive control strategy. IEEE Intell. Transp. Syst. Mag. 2016, 8, 90-103. [CrossRef]

12. Rapeti1, A.; Rao, A.A. Optimization and simulation of electric ship with low voltage AC/DC hybrid power system. Int. J. Sci. Res. 2014, 3, 2159-2166.

13. Mashayekh, S.; Butler-Purry, K.L. An Integrated security-constrained model-based dynamic power management approach for isolated microgrids in All-Electric Ships. IEEE Trans. Power Syst. 2015, 30, 2934-2945. [CrossRef]

14. Tafanidis, K.K.; Taxeidis, K.D.; Tsekouras, G.J.; Kanellos, F.D. Optimal operation of war-ship electric power system equipped with energy storage system. J. Comput. Model. 2013, 3, 41-60.

15. Kanellos, F.D. Optimal power management with GHG emissions limitation in All-Electric Ship power systems comprising energy storage systems. IEEE Trans. Power Syst. 2014, 29, 330-339. [CrossRef]

16. Anvari-Moghaddam, A.; Dragicevic, T.; Meng, L.; Sun, B.; Guerrero, J.M. Optimal planning and operation management of a ship electrical power system with energy storage system. In Proceedings of the 42nd Annual Conference of the IEEE Industrial Electronics Society, Florence, Italy, 23-26 October 2016.

17. Zahedi, B.; Norum, L.E.; Ludvigsen, K.B. Optimized efficiency of All-Electric Ships by DC hybrid power systems. J. Power Sources 2014, 255, 341-354. [CrossRef]

18. Kanellos, F.D.; Prousalidis, J.M.; Skouras, G.J. Control system for fuel consumption minimization-gas emission limitation of full electric propulsion ship power systems. J. Eng. Marit. Environ. 2014, 228, 17-28. [CrossRef] 
19. Kanellos, F.D.; Tsekouras, G.J.; Hatziargyriou, N.D. Optimal demand side management and power generation scheduling in All Electric Ship. IEEE Trans. Sustain. Energy 2014, 5, 1166-1175. [CrossRef]

20. Feng, X.; Butler-Purry, K.L.; Zourntos, T. Multi-agent system-based real-time load management for all-electric ship power systems in DC zone level. IEEE Trans. Power Syst. 2012, 27, 1719-1728. [CrossRef]

21. Tang, D.; Yan, X.; Yuan, Y.; Wang, K.; Qiu, L. Multi-agent Based Power and Energy Management System for Hybrid Ships. In Proceedings of the International Conference Renewable Energy Research and Application (ICRERA), Palermo, Italy, 22-25 November 2015; pp. 383-387.

22. Feng, X.; Butler-Purry, K.L.; Zourntos, T. A Multi-agent system framework for real-time electric load management in MVAC All-Electric ship power systems. IEEE Trans. Power Syst. 2015, 30, 1327-1336. [CrossRef]

23. Seenumani, G.; Sun, J.; Peng, H. A hierarchical optimal control strategy for power management of hybrid power systems in all electric ships applications. In Proceedings of the 49th IEEE Conference Decision \& Control (CDC), Atlanta, GA, USA, 15-17 December 2010; pp. 3972-3977.

24. Larsson, L.; Raven, H.C. The Principles of Naval Architecture Series: Ship Resistance and Flow; Society of Naval Architects and Marine Engineers: Jersey City, NJ, USA, 2010.

25. Woud, H.K.; Stapersma, D. Design of Propulsion and Electric Power Generation Systems; Institute of Marine Engineers: Bellevue, WA, USA, 2002.

26. International Maritime Organization (IMO). Prevention of Air Pollution from Ships; MARPOL 73/78 Annex VI; Technical Report; IMO: London, UK, 2004.

27. International Maritime Organization (IMO). RESOLUTION MEPC.213(63): 2012 Guidelines for the Development of a Ship Energy Efficiency Management Plan (SEEMP). 2012. Available online: http:/ / www.imo.org/OurWork/Environment/PollutionPrevention/AirPollution/Documents / Technical\%20and\%20Operational\%20Measures/MEPC.213\%2863\%29.pdf (accessed on 1 August 2016).

28. International Maritime Organization (IMO). MEPC.1/Circ.684: Guidelines for Voluntary Use of the Ship Energy Efficiency Operational Indicator. 2009. Available online: http:/ /www.imo.org/blast/blastDataHelper. asp?data_id=26531\&filename=684.pdf (accessed on 1 August 2016).

29. Anvari-Moghaddam, A.; Seifi, A.R.; Niknam, T. Multi-operation management of a typical microgrid using particle swarm optimization: A comparative study. Renew. Sustain. Energy Rev. 2012, 16, 1268-1281. [CrossRef]

30. Anvari-Moghaddam, A.; Seifi, A.R.; Niknam, T.; Alizadeh Pahlavani, M.R. Multi-objective operation management of a renewable micro grid with back-up micro turbine/fuel cell/battery hybrid power source. Energy 2011, 36, 6490-6507. [CrossRef]

31. Singhal, P.K.; Sharma, R.N. Dynamic programming approach for solving power generating unit commitment problem. In Proceedings of the 2nd International Conference on Computer and Communication Technology (ICCCT), Allahabad, India, 15-17 September 2011; pp. 298-303. 